\title{
Analysis of Transportation Selection for Travel Work
}

\author{
Abdillah Arif Nasution ${ }^{1 *}$ and Keulana Erwin ${ }^{1}$ \\ ${ }^{1}$ University of Sumatera Utara., Department of Accounting, Medan, Indonesia; Email: \\ badinst@usu.ac.id, keulana@usu.ac.id
}

*Corresponding Author: Abdillah Arif Nasution

\begin{abstract}
The paper discusses the optimizing possibilities in terms of use of public transportation that is very necessary considering the difficulty of increasing the capacity of the road with widen road infrastructure in an effort to manage "supply". Therefore, an alternative approach when managing "demand" for transportation system can be controlled. This is especially needed in settlements newly developed rapidly in Deli Serdang Regency, namely in the Galang Region. The region Galang area with a population of 613 working people with details of 189 civil servants and 424 private employees who the majority (94\%) use private transportation. One aspect that is studied within this manuscript is the amount of transportation costs of travel to work using private transportation (motorcycle) and public transportation (angkot or mikrolet). Transportation selection modeling is done using the Bi-nomial Model Binary Logit. Based on the analysis of the results obtained, it can be concluded that, if the difference in transportation costs with private transport getting bigger, the opportunities to use this mode will increase. The balance between the costs and using private and public transport is maintained if the costs of private transport are 1.4 times greater than the cost public transportation.
\end{abstract}

Keywords: Transport selection, work trip, transport costs, binary logit model

\section{Introduction}

The properties of the transportation system are multi transportation, multidisciplinary and multisectoral. These traits become multi-problems (problems become complex). This was experienced in the Galang Area. The impact of the slow anticipation the development of demand by related institutions in the region has resulted repair cannot be done in a manner comprehensive and create new problems.

The rapid development and conversion of land functions into settlements has led to a high rise in movement, especially for working in this Galang area. Furthermore, the agglomeration will have 
an impact the increasingly complex transportation problems that must immediately get serious treatment.

The purpose of this study is to analyze the costs that must be incurred by residents to the workplace by comparing when using private transportation and using public transportation (angkot or mikrolet) and to analyze the magnitude of opportunities people choose public transportation.

\section{Literature Review}

Mode selection is very difficult to model even though it only involves two types modes (public and private transportation). Thing this is caused by many factors which is difficult to quantify, for example comfort, safety, reliability and vehicle availability when needed.

Factors that can affect the use of modes can be grouped in terms of the characteristics of road users, features movement, features of modal facilities, and features of the city or zone. The choice of a good mode must consider all factors exist in these characteristics.

\subsection{Select of Mode Transportation}

As already stated that the decision to use certain modes are greatly influenced by factors according to the characteristics of road users, for example: availability or ownership private vehicles, driving license, income and the necessity to use modes to work or to deliver children to school [1,3]. In addition to the influence of these factors, the election was also determined influenced by other factors, namely travel time, transportation costs, space availability and the amount of parking fees, comfort and safety, so that the choice of transportation mode is very important in transportation planning [2-4].

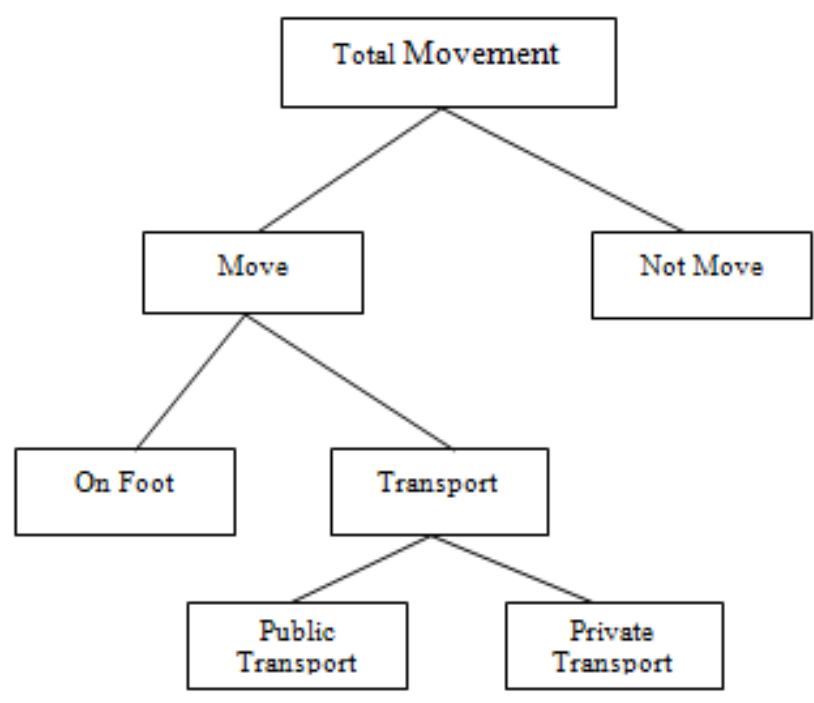

Fig. 1 Transportation Mode Selection Process

In this study the user is assumed the way to choose between moving and not move. If you make a move, you will be selected for mode transport and on foot, then if you choose to use modes, you 
are required to choose two usage options public transportation or private transportation, as the process shown in Figure 1.

\subsection{Costs Definition}

The basic cost is the amount of sacrifice incurred to produce one unit of transportation service production unit. To make it easier to calculate costs principal are grouped according to their relationship to the production of services produced, consists of: direct costs (direct cost) relating to service products produced like fuel usage and vice versa indirect costs (indirect costs) are costs that are not related to the service product produced [5-7].

Basic costs for transportation services general, where the basic cost is the magnitude of the cost charged to each passenger of a one-time vehicle traveling from the origin to the destination point of travel, the time value of a person at in public transportation and the value of waiting for public transportation, while the basic cost of private transportation, where the basic cost is the usage fee fuel spent for one trip, time value in or using a vehicle for one trip [1].

Mathematically, it can be expressed as follows:

- Costs of Private Transportation

$$
C p=\Psi D+Z X 2+C
$$

where: $C p$ is cost of private vehicle [Rp]; $\Psi$ is vehicle operating costs per unit distance [Rp]; $D$ is distance from movement $[\mathrm{km}] ; Z$ is value of passenger time per unit time $[\mathrm{Rp}] ; X 2$ is time in the vehicle [min]; $C=$ parking fee $[\mathrm{Rp}]$.

- Costs of Public Transportation

$$
C u=\not D+Z X 1+Z X 2+X 3
$$

where: $C u$ is cost of public transportation [Rp]; $\Phi$ is rate per unit distance [Rp]; $D$ is distance of movement $[\mathrm{km}] ; Z$ is passenger time value per unit time [Rp]; $X 1$ is waiting time for vehicles [min]; $X 2$ is time in the vehicle [min]; $X 3$ is additional costs such as terminal fees [Rp].

\section{Research Method}

The value of a person's time really depends on the purpose of the trip (business destination / work and non-business) the amount of which can describe the service time consumers provided by the road to road users [2]. The value of a business trip / - work is quantified as value time per hour, assuming the same as the hourly value of income per capita $[8,9]$.

To calculate the time value, research results are used on several provinces with an average value in 2014 in three zones as shown in Table 1. 
Table 1 Average Time Value. Source: authors

\begin{tabular}{cc}
\hline Zone & Passenger Time Value \\
\hline High & Rp. 600,-/Day \\
\hline Medium & Rp. 470,-/Day \\
\hline Low & Rp. 340,-/Day \\
\hline
\end{tabular}

The values summarized in Table 1 are used to obtain look for the value of Future Value, as follows.

$$
F=P(1+i)^{\mathfrak{y}}
$$

The $\mathrm{F}$ value is calculated up to years 2018 , obtained for:

$$
F=R p .3,000.00 / \text { day }
$$

With this analysis the Average Value Time in 2018, obtained like in Table 2, while the number of passengers for each type of study vehicle presented in Table 3.

Table 2 Average Time Value 2018. Source: authors

\begin{tabular}{cc}
\hline Zone & Passenger Time Value \\
\hline High & Rp. 3.800,-/Day \\
\hline Medium & Rp. 3.000,-/Day \\
\hline Low & Rp. 2.200,-/Day \\
\hline
\end{tabular}

Table 3 The number of passengers for each vehicle type. Source: authors

\begin{tabular}{cc}
\hline Type & Passenger \\
\hline Passenger pick-up & 14 \\
\hline Bus & 37 \\
\hline Car & 7 \\
\hline Motorcycle & 3 \\
\hline
\end{tabular}

\subsection{Site Selection}

Choosing the location of the village of Dalung as study area because most of the land use has changed to become region settlements, so that this area has a greater trip generation compared to the attraction of his trip, and as a mode used by motorbikes for private transportation and angkot or mikrolet as transportation general. 


\subsection{Analytical Framework}

The analytical framework is in sequence from the stages of work as a reference to get the expected results according to the final aim of this study, start from preliminary studies, problem identification and goal setting, literature study, questionnaire design, preliminary survey, data collection, data analysis and grouping, model calibration, analysis according to the model, and finally conclusions are obtained and advice.

\subsection{Data Collection}

The data collected consists of primary data in the form of transportation costs, population income, and the number of vehicles that are owned, time and distance of travel and age level of the respondent. Other data in the form of secondary data include: population data, inflation data, and economic growth data.

The data obtained is recapitulated and processed with data classification steps consisting of editing and coding data and analysis data both with descriptive methods and analysis methods. This process is done to get processed data which is then processed again into stages analysis [3].

\subsection{Stages of Analysis}

In this stage the analysis is carried out on costs, factor based analysis staffing and income level, and simulation equation for regression.

The next stage was calibration using the Logit Model, and analysis using the Binomial-LogitDifference model and the Binomial-Logit-Nisbah model [10-12].

\section{Results and Discussion}

Characteristics of Respondents, Number of Family Cards and Number of Workers. Galang Village located at Deli Serdang. Specifically the village of Galang consists of 23 hamlets each the hamlet is headed by the hamlet head with a total of 4,193 households, so the number the sample is 409 samples. The results of a survey of a number of residents in six villages in Deli Serdang District can be seen in Table 4-8. 
Table 4 The number of working families. Source: authors

\begin{tabular}{ccccc}
\hline Numb. & $\begin{array}{c}\text { The Number of } \\
\text { Workers }(\mathrm{X})\end{array}$ & $\begin{array}{c}\text { The Number } \\
\text { Families } \\
\text { Surveyed }(\mathrm{f})\end{array}$ & $\begin{array}{c}\text { Total Workers } \\
(\mathrm{f} . \mathrm{x})\end{array}$ & $\begin{array}{c}\text { Percentage } \\
(\%)\end{array}$ \\
\hline 1. & 0 & 43 & 0 & 10,51 \\
\hline 2. & 1 & 188 & 288 & 45,97 \\
\hline 3. & 2 & 126 & 252 & 30,81 \\
\hline 4. & 3 & 39 & 117 & 9,54 \\
\hline 5. & 4 & 9 & 36 & 2,20 \\
\hline 6. & 5 & 4 & 20 & 0,98 \\
\hline \multicolumn{6}{c}{ Average number of working family members $=1,498$ workers $\approx 2$ workers } \\
\hline \multicolumn{6}{c}{ Total } & 409 & & \\
\hline
\end{tabular}

Table 5 Results Home Interview Survey. Source: authors

\begin{tabular}{cccc}
\hline Numb. & $\begin{array}{c}\text { Total Income } \\
\text { (Rupiah) }\end{array}$ & $\begin{array}{c}\text { Total Respondents } \\
\text { (Person) }\end{array}$ & $\begin{array}{c}\% \text { of the number } \\
\text { Respondents }\end{array}$ \\
\hline 1. & $>2.500 .000$ & 359 & $58,6 \%$ \\
\hline 2. & $\begin{array}{c}2.500 .000 \text { to } \\
3.500 .000\end{array}$ & 238 & $38,8 \%$ \\
\hline 3. & $>3.500 .000$ & 16 & $2,6 \%$ \\
\hline \multicolumn{4}{r}{ Average Rp. 2.215.000,- } \\
\hline
\end{tabular}

Table 6 The choice of transportation mode is based on employment status. Source: authors

\begin{tabular}{ccc}
\hline Employee & Private Transportation & Public Transportation \\
\hline Government & 180 & 9 \\
\hline Private & 398 & 26 \\
\hline Total & 578 & 35 \\
\hline
\end{tabular}

Table 7 Characteristics of respondents based on age level. Source: Authors

\begin{tabular}{cccc}
\hline Numb. & Age (Year) & Private transportation & Public Transportation \\
\hline 1. & $\leq 30$ & 193 & 15 \\
\hline 2. & $>30$ & 385 & 20 \\
\hline \multicolumn{2}{c}{ Total } & 578 & 35 \\
\hline
\end{tabular}

Table 8 Characteristics of Mode Use in conditions Revealed Preferences and Stated Preferences respondents based on age level. Source: authors

\begin{tabular}{ccc}
\hline Mode & $\begin{array}{c}\text { Revealed } \\
\text { Preferences }\end{array}$ & Stated Preferences \\
\hline Private & 578 & 593 \\
\hline Public & 20 & 20 \\
\hline
\end{tabular}




\subsection{General Public Transportation Costs}

General costs (Generalized Cost) for public transportation is the cost to be paid or the cost of time in and vehicle waiting time or value passenger time. In calculating the time value is also calculated against the value of inflation in North Sumatra, where for the Galang Region is considered a medium zone, so the passenger time value $(Z)$ from 2014- 2018 is calculated as follows:

- $\quad$ Time value $=$ Time zone value of passenger zone medium $\mathrm{x}$ average inflation,

then the value of time $=1500 \times(5.97 \%+11.31 \%+4.30 \%+5.91 \%+9.62 \%) / 5=\mathrm{Rp} .11,133.00 /$ day or Rp463.87 / hour or Rp7 , 73 / minute.

Thus, it is obtained:

- $\quad$ Value of passenger time $(Z)=$ Number of passenger vehicles sampled $x$ time value.

Value of passenger time $=7 \times \mathrm{Rp} 7,73=\mathrm{Rp} .54 .11 \approx \mathrm{Rp} .55 .00 /$ minute so based on formula (2), the general cost for public transportation for a distance of $9 \mathrm{~km}$, the waiting time for a vehicle is 10 minutes and the trip time is 30 minutes with ignoring additional costs can be calculated as follows:

$$
\begin{gathered}
C u=\phi D+Z X 1+Z X 2+X 3 \\
C u=300 * 9+55 * 10+55 * 30+0 \\
C u=2700+550+1650=\operatorname{Rp} 4.900,-
\end{gathered}
$$

\subsection{General Cost for Private Transportation}

General costs (Generalized Cost) for private transportation are the costs that must be paid including parking fees [13-15]. Galang area is considered to be of a medium zone, so the passenger time values (Z) from 2014 - 2018 are calculated as follows:

Passenger time value $(Z)=$ Number of passenger vehicles sampled $\mathrm{x}$ time value.

Table 9 General Costs Transportation. Source: Authors

\begin{tabular}{ccc}
\hline Group & CPr (Rp) & Cpu (Rp) \\
\hline K1 & $1.694,00$ & $4.716,00$ \\
\hline K2 & $1.685,00$ & $4.667,00$ \\
\hline K3 & $1.658,00$ & $4.479,00$ \\
\hline K4 & $1.712,00$ & 4.819 .00 \\
\hline K5 & $1.715,00$ & $4.825,00$ \\
\hline K6 & $1.702,00$ & $4.755,00$ \\
\hline
\end{tabular}

The value of passenger time $=1.5 x \operatorname{Rp} 7.73=\operatorname{IDR} 11,595 \approx$ IDR 12,00 / minute. Meanwhile vehicle operating costs $(V O C)$ for private vehicles, for motorcycle:

$$
V O C=a+b / V+c^{*} V^{2}
$$


where: $\mathrm{V}$ is average speed of $40 \mathrm{~km} / \mathrm{h}$; $\mathrm{a}$ is constant of 24 ; b is coefficient with a value of 596 ; $\mathrm{c}$ is coefficient with a value of 0.00370 ; then: $V O C=24+(596 / 40)+(0.00370 * 402)$ VOC $=I D R$ $44.82 / \mathrm{km}$.

Based on formula (1), the general cost for private transportation for a distance of $9 \mathrm{~km}$, and a 30 minute trip length with a parking fee of Rp1,000.00 can be calculated as follows:

$$
\begin{gathered}
C p=\Psi D+Z X 2+C \\
C p=44.82 * 9+12 * 30+1000 \\
C p r=403,38+360+1000=\mathrm{Rp} 1.763,38
\end{gathered}
$$

\subsection{Modeling and Analysis}

The workers in this study are distinguished based on employment status, namely private employees and civil servants, level income and age to be able to aggregate the data obtained, as the following: K1: Civil servants earn less than Rp. 2,500,000.00

K2: Civil servants earn Rp. 2,500,000.00-Rp3,5000,000.00

K3: Civil servants earn more than Rp. 3,500,000.00

K4: Private employees earn less than IDR 2,500,000.00

K5: Private employees earn Rp. 2,500,000.00-Rp3,5000,000.00

K6: Private employees earn more than Rp. 3,500,000.00

Based on general cost calculations good use of private transportation (bicycles motorcycle) and public transportation (angkot or microbuses) and based on staffing status and income level the average analysis results are obtained.

With analysis using the method Linear regression analysis for the binomial logit difference model and the binomial logit model ratio, obtained results as in Table 10.

\begin{tabular}{|c|c|c|c|c|c|c|c|c|c|c|}
\hline & $\mathrm{Cpr}$ & $\mathrm{Cpu}$ & $\frac{\text { Cpr-Cpu }}{(\mathrm{Xi})}$ & $\begin{array}{l}\mathrm{PPr} \\
(\%)\end{array}$ & $\begin{array}{l}\mathrm{PPu} \\
(\%)\end{array}$ & $\begin{array}{c}\text { Loge }\{(1 \\
-\mathrm{Pi}) / \mathrm{Pi}\} \\
(\mathrm{Yi})\end{array}$ & $\mathrm{XiYi}$ & Xi 2 & $\begin{array}{c}\exp (A+B \\
X i)\end{array}$ & $\begin{array}{c}\mathrm{P}=1 /\{1+\mathrm{e} \\
\mathrm{xp}(\mathrm{A}+\mathrm{BX} \\
\text { i) }\}\end{array}$ \\
\hline 1. & $1.694,00$ & $4.716,00$ & $3.022,00$ & 0,8889 & 0,1111 & 0,903 & 2729,28560 & 9132484 & 0,20429 & 0,83037 \\
\hline 2. & $1.685,00$ & $4.667,00$ & $2.982,00$ & 0,9839 & 0,0161 & $-1,786$ & 5326,22500 & 8892324 & 0,21493 & 0,82309 \\
\hline 3. & $1.658,00$ & $4.479,00$ & $2.821,00$ & 0,8333 & 0,1667 & $-0,699$ & $-1971,5003$ & 7958041 & 0,26367 & 0,79135 \\
\hline 4. & $1.712,00$ & $4.819,00$ & $3.107,00$ & 0,9333 & 0,0667 & $-1,146$ & $-3560,2971$ & 9653449 & 0,18339 & 0,84503 \\
\hline 5. & $1.715,00$ & $4.825,00$ & $3.110,00$ & 0,9727 & 0,0273 & $-1,552$ & $-4826,1486$ & 9672100 & 0,18339 & 0,84553 \\
\hline 6. & $1.702,00$ & $4.755,00$ & $3.053,00$ & 0,7000 & 0,3000 & $-0,368$ & $-1123,4331$ & 9320809 & 0,19641 & 0,83584 \\
\hline & & $\sum=$ & 18095 & & & $-6,454$ & $-19536,890$ & 54629207 & & \\
\hline \multicolumn{10}{|c|}{$\mathrm{B}=\left\{\mathrm{N}^{*} \sum \mathrm{XiYi}-\left(\sum\left(\mathrm{Xi}^{*} \mathrm{Yi}\right)\right\} /\left\{\mathrm{N}^{*} \sum \mathrm{Xi} 2-\left(\sum \mathrm{Xi}\right) 2\right\}\right.$} & 0,001 \\
\hline \multicolumn{10}{|c|}{$\mathrm{A}=\mathrm{Y}-\mathrm{B} \cdot \mathrm{X}$ Inf. : Y (Y Average) dan X (X Average) } & 2,24800 \\
\hline
\end{tabular}

Table 10 Calculation of linear regression analysis method for the binomial-logit-difference model.

Source: authors 
From Table 10, an equation for the binomial-logit-difference model is obtained and then entered into the simultaneous equation with the aim of getting results, where $\alpha$ and $\beta$ are a parameter model of a regression equation, namely: $\mathrm{Y}=\alpha+\beta \mathrm{X} ; \mathrm{Y}=2,248-0,001 \mathrm{X}$ Or $\log \{(1$ $\mathrm{Pp}) / \mathrm{Pp}\}=\alpha+\beta(\mathrm{Cp}-\mathrm{Cu}) \log \{(1-\mathrm{Pp}) / \mathrm{Pp}\}=2,248-0,001(\mathrm{Cp}-\mathrm{Cu})$.

\section{Conclussion}

Based on the results of modeling analysis logit-difference binomials, it was found that if the difference in the cost of public transportation with greater personal transport then the opportunity for using transportation personal will become greater.

If the cost of both modes is the same (difference in cost equal to zero), then using the private vehicles will be bigger. To get the same opportunity, subsidies must be given to public transportation at least $\operatorname{Rp} 2,800.00$.

Next, based the results of the binomial logit modeling analysis, it was found that at the conditions Private transport costs are the same as fees public transportation, about $79 \%$ of people will choose to use private transportation. To attract public interest in using public transportation, then public transport costs must be cheaper by 1.4 times compared to private transport costs.

\section{References}

[1] Tamin O.Z. (2003), Perencanaan dan Pemodelan Transportasi, Penerbit ITB Bandung.

[2] Sugiyono. (2012). Metode Penelitian Kuantitatif \& Kualitatif. Bandung, Indonesia: Alfabeta.

[3] Kuncoro, M. (2014). Metode Riset untuk Bisnis dan Ekonomi, $4^{\text {th }}$ edition, Jakarta, Indonesia: Erlangga.

[4] Nasution, A.A., Azmi, Z., Siregar, I. \& Erlina, I. (2018). Impact of air transport on the Indonesian economy. MATEC Web of Conferences. 236. DOI: 10.1051/matecconf/.

[5] Engebrethsen, E. \& Dauzère-Pérès, S. (2019). Transportation mode selection in inventory models: A literature review. European Journal of Operational Research. 279(1), 1-25. DOI:10.1016/j.ejor.2018.11.067.

[6] Frank, S., Berk, S., Hernandez, L., Hogarth, P., Shill, H.A., Siddiqi, B. \& Simon, D.K. (2019). Transportation innovation to aid Parkinson disease trial recruitment. Contemporary Clinical Trials Communications. 16. DOI:10.1016/j.conctc.2019.100449.

[7] Khordagui, N. (2019). Parking prices and the decision to drive to work: Evidence from California. Transportation Research Part A: Policy and Practice. 130, 479-495. DOI:10.1016/j.tra.2019.09.064. 
[8] McCormack, G.R., Koohsari, M.J., Oka, K., Friedenreich, C.M., Blackstaffe, A., Alaniz, F.U. \& Farkas, B. (2019). Differences in transportation and leisure physical activity by neighborhood design controlling for residential choice. Journal of Sport and Health Science. 8(6), 532-539. DOI:10.1016/j.jshs.2019.05.004.

[9] Zhang, X. \& Huang, H. (2019). Vehicle classification based on feature selection with anisotropic magnetoresistive sensor. IEEE Sensors Journal. 19(21), 9976-9982. DOI:10.1109/JSEN.2019.2928828.

[10] Jianchuan, X. (2010). Modeling the generation and organization of household non-work activity: A case study of Beijing. In International Conference on Optoelectronics and Image Processing, ICOIP 2010, 2, 8-11. DOI:10.1109/ICOIP.2010.32.

[11] Liu, Y. \& Li, Y. (2018). Characteristic variables and behavior analysis of simple and complex non-work trip chains base on binary logit model. In CICTP 2017: Transportation Reform and Change - Equity, Inclusiveness, Sharing, and Innovation; Proceedings of the 17th COTA International Conference of Transportation Professionals, 2018-January, 3811-3821.

[12] Xianyu, J. \& Juan, Z. (2011). Generation and organization of household non-work activity stops. Jiaotong Yunshu Xitong Gongcheng Yu Xinxi/Journal of Transportation Systems Engineering and Information Technology. 11(4), 124-128.

[13] Sahu, P. K., Sharma, G. \& Guharoy, A. (2018). Commuter travel cost estimation at different levels of crowding in a suburban rail system: A case study of Mumbai. Public Transport. 10(3), 379-398. DOI: 10.1007/s12469-018-0190-6.

[14] BARTUŠKA, Ladislav, Karel JEŘÁBEK a Li CHENGUANG. Determination of Traffic Patterns on urban roads. Communications, Žilina: Žilinská univerzita v Žilině, EDIS, 2017, roč. 19, č. 2, s. 103-108. ISSN 1335-4205.

[15] HANZL, Jiří, Ladislav BARTUŠKA, Elena ROZHANSKAYA a Petr PRŮŠA. Application of Floyd's Algorithm on Transport Network of South Bohemian Region. Communications : scientific letters of the University of Žilina, Žilina: The University of Žilina, 2016, Volume 18 , č. 2, s. 68-71. ISSN 1335-4205. 